\title{
Prevalence, predictors and clinical significance of Blastocystis sp. in Sebha, Libya
}

\author{
Awatif M Abdulsalam', Init Ithoi ${ }^{1^{*}}$, Hesham M Al-Mekhlafi ${ }^{1,5^{*}}$, Abdul Hafeez Khan ${ }^{2}$, Abdulhamid Ahmed $^{3}$,
} Johari Surin ${ }^{1}$ and Joon Wah Mak ${ }^{4}$

\begin{abstract}
Background: Blastocystis sp. has a worldwide distribution and is often the most common human intestinal protozoan reported in children and adults in developing countries. The clinical relevance of Blastocystis sp. remains controversial. This study was undertaken to determine the prevalence of Blastocystis infection and its association with gastrointestinal symptoms among outpatients in Sebha city, Libya.

Methods: A total of 380 stool samples were collected from outpatients attending the Central Laboratory in Sebha, Libya for routine stool examination. The presence of Blastocystis sp. was screened comparing light microscopy of direct smears against in vitro cultivation. Demographic and socioeconomic information were collected with a standardized questionnaire.

Results: The overall prevalence of Blastocystis infection was $22.1 \%$. The prevalence was significantly higher among patients aged $\geq 18$ years compared to those aged $<18$ years $\left(29.4 \%\right.$ vs $\left.9.9 \% ; x^{2}=19.746 ; P<0.001\right)$, and in males compared to females $\left(26.4 \%\right.$ vs $\left.17.5 \% ; x^{2}=4.374 ; P=0.036\right)$. Univariate analysis showed significant associations between Blastocystis infection and the occupational status $(P=0.017)$, family size $(P=0.023)$ and educational level $(P=0.042)$ of the participants. Multiple logistic regression analysis confirmed that the age of $\geq 18$ years $(\mathrm{OR}=5.7$; $95 \% \mathrm{Cl}=2.21 ; 9.86)$ and occupational status $(\mathrm{OR}=2.2 ; 95 \% \mathrm{Cl}=1.02,4.70)$ as significant predictors of Blastocystis infection among this population. In those who had only Blastocystis infection but no other gastrointestinal parasitic infections, the prevalence of gastrointestinal symptoms was higher compared to those without Blastocystis infection (35.3\% vs $\left.13.2 \% ; x^{2}=25.8 ; P<0.001\right)$. The most common symptoms among these patients were abdominal pain (76.4\%), flatulence (41.1\%) and diarrhoea (21.5\%).

Conclusions: Blastocystis sp. is prevalent and associated with gastrointestinal symptoms among communities in Sebha city, Libya. Age and occupational status were the significant predictors of infection. However, more studies from different areas in Libya are needed in order to delineate the epidemiology and clinical significance of this infection.
\end{abstract}

Keywords: Blastocystis, Gastrointestinal symptoms, Sebha, Libya

\section{Background}

Blastocystis sp. is one of the most common intestinal protozoa found in the human intestinal tract. Blastocystis infection is widely distributed throughout the world with a high prevalence in developing countries in the tropics and subtropics [1,2]. Human infection is associated with poor personal hygiene, lack of sanitation, exposure to animals,

\footnotetext{
*Correspondence: init@um.edu.my; halmekhlafi@yahoo.com

'Department of Parasitology, Faculty of Medicine, University of Malaya, Kuala Lumpur 50603, Malaysia

${ }^{5}$ Department of Parasitology, Faculty of Medicine and Health Sciences, Sana'a University, Sana'a, Yemen

Full list of author information is available at the end of the article
}

and consumption of contaminated food or water [3,4]. Although it was discovered almost a century ago Blastocystis pathogenicity is reported to be controversial [4-6]. The clinical manifestations among the symptomatic individuals are mainly nonspecific such as diarrhoea, abdominal pain, nausea, fatigue, vomiting, anorexia, and flatulence $[3,4,6]$. The routine diagnosis of the infection is currently based on microscopic identification of the protozoa in the direct smears carried out before or after cultivation of the faecal sample [4].

In Libya, previous studies in Sebha, city showed that Blastocystis sp. was frequently isolated from symptomatic

\section{Biomed Central}


patients $[7,8]$. Detection of the Blastocystis sp. is not routinely performed in most Libyan laboratories, so the prevalence and predictors of Blastocystis infection are poorly known. Given the lack of epidemiological information on Blastocystis sp. in Libya, this study was undertaken to determine the prevalence and associated predictors of Blastocystis infection among outpatients attending the Central Laboratory in Sebha, Libya.

\section{Methods}

\section{Study area and study population}

This cross-sectional study was carried out in Sebha city, Libya, about $800 \mathrm{~km}$ south of Tripoli (longitude $14.42^{\circ} \mathrm{E}$, latitude $27.03^{\circ} \mathrm{N}$ ) (Figure 1 ). The city is situated in the Fezzan valley with a total area of $15,330 \mathrm{~km}^{2}$ and a total population of 130,000 people. The area is characterized by desert climate, dry and hot weather and low rainfall. Agriculture is the main occupation of the people and underground wells are the main source of water. Data collection was carried out between August and November 2010.

A total of 380 stool samples were collected from outpatients at Sebha Central Laboratory. The samples were collected as a part of a routine medical examination of people living in the city or within the vicinity. Prior to data collection, the nature of the study was explained to the participants and informed verbal consents were obtained. Demographic, socioeconomic, environmental and behavioural information and history of gastrointestinal (GI) symptoms were collected with a standardized questionnaire (face-to-face interviews). Participants who tested positive for Blastocystis infection were divided into symptomatic hosts $(n=54)$ or asymptomatic hosts $(n=30)$, based on the presence or absence of GI symptoms. The protocol of this study was approved by the Medical Ethics Committee of the University of Malaya Medical Center, Kuala Lumpur. Based on this ethical clearance, permission to conduct this study was also given by the Faculty of Medicine, University of Sebha and Sebha Central laboratory authorities before the commencement of the study.

\section{Stool examination}

A single faecal sample was collected from each patient in a clean plastic container. The specimens were examined for the presence of intestinal parasites and cultured for Blastocystis sp. at the Central Laboratory, Sebha, Libya. No further information was available on potential viral or bacterial infections.

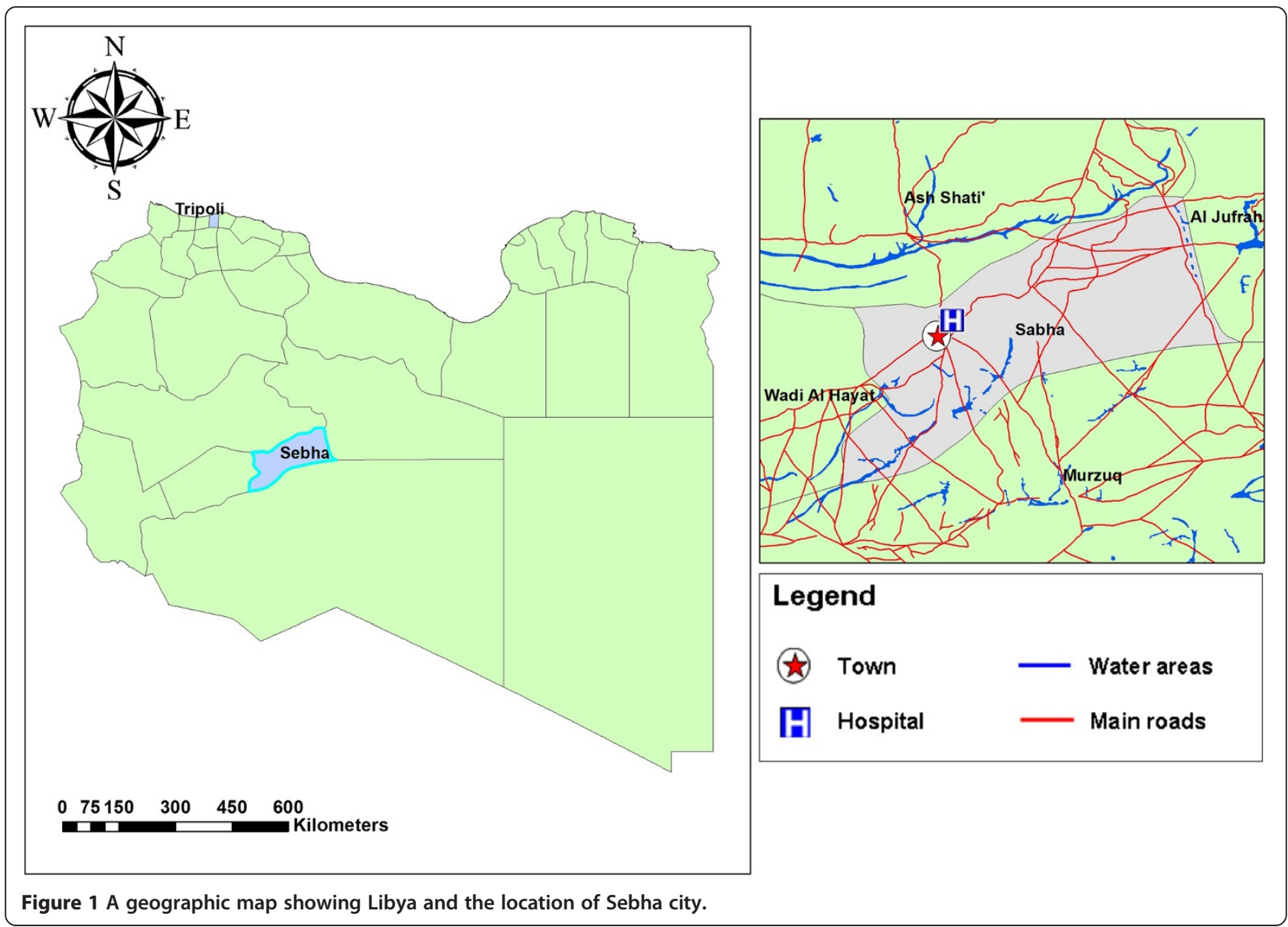




\section{Detection of Blastocystis sp}

The fecal samples were cultured in Jones' medium supplemented with $10 \%$ horse serum [9]. For each culture, approximately $50 \mathrm{mg}$ of stool was inoculated into a $15-\mathrm{ml}$ screw-cap tube containing $5 \mathrm{ml}$ of Jones' medium. All inoculated tubes were tightly-closed, placed in a rack and incubated at $37^{\circ} \mathrm{C}$. The medium in each of these tubes was replaced with the new complete Jones' medium every alternate day starting from day 2 of cultivation. This was carried out by discarding about $4.0 \mathrm{ml}$ of the medium at the top level (without disturbing the pellet) and replaced by $4.0 \mathrm{ml}$ of new complete Jones' medium. The presence of Blastocystis sp. was observed daily for 14 days of cultivation, by placing 1 drop of the cultured sediment onto a glass slide, covered with a cover-slip and viewed (X100 and X400 objectives) under light microscopy. Positive cultures were defined by the detection of any form of Blastocystis sp. (i.e. vacuolar, granular, amoeboid, and cystic forms), as in our previous published report [3].

\section{Detection of other intestinal parasites}

The stool samples were examined on the day of collection. Wet mount preparations of the stool samples were examined using light microscopy. In addition, specimens were concentrated by a formalin-ethyl acetate sedimentation technique. Sediments were then examined as a wet mount in saline and iodine for detection of protozoa, eggs and larvae of intestinal helminthes. Permanent stained smears were carried out by the modified ZiehlNeelsen stain for intestinal coccidian parasites [10].

\section{Statistical analysis}

Statistical analysis was performed using the Statistical Package for Social Sciences for Windows (SPSS), version 11.5 (SPSS Inc, Chicago, IL, USA). Demographic and socioeconomic characteristics were treated as categorical variables and presented as frequencies and percentages. Pearson's Chi Square test was used to examine the associations of Blastocystis prevalence with the demographic and socioeconomic factors. Odds ratio (OR) and 95\% confidence intervals (CI) were computed. A multiple logistic regression model was performed to identify the significant predictors of infection. All $\mathrm{P}$ values $\leq 0.05$ were considered statistically significant.

\section{Results}

In this study, stool specimens were collected from a total of 380 patients (197 males and 183 females) aged from 1 to 75 years (median age $=25$ years, inter-quartile range $=$ 9-41 years). The general characteristics of the patients are shown in Table 1 . The patients were from Sebha city and its surroundings. Almost half of the participants had a low level of education (31.6\% had no formal education and $17.6 \%$ had primary education). Similarly, about
Table 1 General characteristics of the participants $(n=380)$

\begin{tabular}{ll}
\hline Characteristics & Frequency (\%) \\
\hline Age group (years): & $238(62.6)$ \\
$\geq 18$ & $142(37.4)$ \\
$<18$ & \\
Gender: & $197(51.8)$ \\
Male & $183(48.2)$ \\
Female & \\
Socioeconomic status: & $120(31.6)$ \\
Participants' education level (at least 6 years) & $132(44.0)$ \\
Working participants & $222(58.4)$ \\
Large family size ( $\geq 7$ members) & $138(36.3)$ \\
Treated drinking water (filtered or boiled) & $44(11.6)$ \\
Presence of animals in the house & $16(4.2)$ \\
History of recent overseas travel & $153(40.3)$ \\
Presence of gastrointestinal (Gl) symptoms &
\end{tabular}

half of them had high level of education (39.5\% had secondary education and $11.3 \%$ had university degree). Moreover, all of the houses are built of bricks and concrete and had electricity, piped water and a flush toilet facility. More than half of patient enrolled in the study were asymptomatic while the rest were symptomatic with one or more of following gastrointestinal symptoms: abdominal pain, diarrhoea, flatulence, constipation, vomiting, and nausea.

\section{Prevalence and predictors of Blastocystis infection}

The overall prevalence of Blastocystis infection was $22.1 \%$ (84/380). The association of Blastocystis infection with the demographic and socioeconomic factors was examined using univariate analysis and the results are presented in Table 2. The results showed that the participants aged $\geq$ 18 years had a higher prevalence of Blastocystis infection than those aged $<18$ years $\left(29.4 \%\right.$ vs $9.9 \% ; x^{2}=19.746$; $P<0.001)$. Similarly, a significantly higher prevalence of infection was reported in males as compared to females (26.4\% vs $\left.17.5 \% ; x^{2}=4.374 ; P=0.036\right)$. The prevalence of infection was significantly higher among those who were working $\left(31.8 \%\right.$ vs $\left.19.6 \% ; x^{2}=5.848 ; P=0.017\right)$ and had low educational level $\left(26.4 \%\right.$ vs $17.6 \%$; $x^{2}=4.250$; $P=0.042)$ compared to their counterparts. On the other hand, those living in families with $\geq 7$ members had significantly lower prevalence of Blastocystis infection than those living in small families $\left(18.0 \%\right.$ vs $27.8 ; x^{2}=5.180$; $P=0.023)$. Multiple logistic regression analysis confirmed the age of $\geq 18$ years $(\mathrm{OR}=5.7 ; 95 \% \mathrm{CI}=2.21,9.86)$ and working status $(\mathrm{OR}=2.2 ; 95 \% \mathrm{CI}=1.02,4.70)$ as significant predictors of blastocystosis among this population 
Table 2 Univariate analysis of potential predictors for Blastocystis infection among the participants $(n=380)$

\begin{tabular}{|c|c|c|c|c|}
\hline \multirow[t]{2}{*}{ Variable } & \multicolumn{2}{|c|}{ Blastocystis infection } & \multirow[t]{2}{*}{ OR $(95 \% \mathrm{Cl})$} & \multirow[t]{2}{*}{$P$} \\
\hline & No. Examined & $\%$ Infected & & \\
\hline \multicolumn{5}{|l|}{ Age } \\
\hline$\geq 18$ years & 238 & 29.4 & $3.8(2.05,7.06)$ & $<0.001^{*}$ \\
\hline$<18$ years & 142 & 9.9 & 1 & \\
\hline \multicolumn{5}{|l|}{ Gender } \\
\hline Male & 197 & 26.4 & $1.7(1.03,2.77)$ & $0.036 *$ \\
\hline Female & 183 & 17.5 & 1 & \\
\hline \multicolumn{5}{|l|}{ Education level } \\
\hline$\leq$ Primary school & 193 & 26.4 & $1.7(1.02,2.75)$ & $0.042^{*}$ \\
\hline$\geq$ Secondary school & 187 & 17.6 & 1 & \\
\hline \multicolumn{5}{|l|}{ Occupational status } \\
\hline Working & 132 & 31.8 & $2.0(1.13,3.24)$ & $0.017^{*}$ \\
\hline Not working & 168 & 19.6 & 1 & \\
\hline \multicolumn{5}{|l|}{ Family size } \\
\hline$\geq 7$ members (large) & 222 & 18.0 & $0.6(0.35,0.93)$ & $0.023^{*}$ \\
\hline$<7$ members & 158 & 27.8 & 1 & \\
\hline \multicolumn{5}{|l|}{ Drinking water } \\
\hline Untreated water & 242 & 23.1 & $1.2(0.70,1.97)$ & 0.520 \\
\hline Treated water (chemical, filtered or boiled) & 138 & 20.3 & 1 & \\
\hline \multicolumn{5}{|l|}{ Presence of animalsin the house } \\
\hline Yes & 44 & 13.6 & $0.5(0.21,1.28)$ & 0.150 \\
\hline No & 336 & 23.3 & 1 & \\
\hline \multicolumn{5}{|l|}{ History of recent overseas travel } \\
\hline Yes & 16 & 31.3 & $1.6(0.55,4.85)$ & 0.360 \\
\hline No & 364 & 21.7 & 1 & \\
\hline \multicolumn{5}{|l|}{ Presence of Gl symptoms } \\
\hline Yes & 153 & 35.3 & $3.6(2.14,5.94)$ & $<0.001^{*}$ \\
\hline No & 227 & 13.2 & 1 & \\
\hline \multicolumn{5}{|l|}{ Abdominal pain } \\
\hline Yes & 131 & 35.9 & $3.2(1.94,5.28)$ & $<0.001^{*}$ \\
\hline No & 249 & 14.9 & 1 & \\
\hline \multicolumn{5}{|l|}{ Diarrhoea } \\
\hline Yes & 41 & 31.7 & $1.8(0.86,3.56)$ & 0.117 \\
\hline No & 339 & 20.9 & 1 & \\
\hline \multicolumn{5}{|l|}{ Flatulence } \\
\hline Yes & 55 & 49.1 & $4.5(2.48,8.26)$ & $<0.001^{*}$ \\
\hline No & 325 & 17.5 & 1 & \\
\hline
\end{tabular}

$O R$, odds ratio; $\mathrm{Cl}$, confidence interval.

* Significant association $(P<0.05)$.

(Table 3). Other variables including type of drinking water, presence of animals at the household and travel history showed no significant association with the prevalence of Blastocystis infection.
Single and multiple infections

Of 380 patients examined, 91 (24\%) were positive for intestinal protozoa. Of these 91 patients, 79 patients were singly infected with Blastocystis sp., 5 patients 
Table 3 Results of multivariate analysis of potential predictors for Blastocystis infection among the participants $(n=380)$

\begin{tabular}{lll}
\hline Variables & $\begin{array}{l}\text { Blastocystis infection } \\
\text { Adjusted OR }(\mathbf{9 5 \%} \mathrm{Cl})\end{array}$ \\
\hline Age ( $\geq 18$ years) & $5.7(2.21,9.86)$ & $0.001^{*}$ \\
Gender (male) & $1.6(0.67,3.55)$ & 0.304 \\
Educational level ( (s primary education) & $1.8(0.86,4.26)$ & 0.113 \\
Occupational status (working) & $2.2(1.02,4.70)$ & $0.045^{*}$ \\
Family size (small) & $0.7(0.32,1.07)$ & 0.063 \\
\hline
\end{tabular}

$O R$, odds ratio; $\mathrm{Cl}$, confidence interval.

* Significant predictors $(P \leq 0.05)$.

were infected with Blastocystis sp. concurrently with four species of intestinal parasites namely Giardia duodenalis, Entamoeba histolytica/dispar, Crptosporidium spp. and Enterobius vermicularis. Moreover, 7 patients were Blastocystis-negative but infected with either Giardia duodenalis or Entamoeba histolytica/dispar.

\section{Symptoms}

Most gastrointestinal symptoms reported by symptomatic patients were nonspecific and included diarrhoea, abdominal pain, flatulence, constipation, nausea, and vomiting. The prevalence of Blastocystis infection was significantly higher among the symptomatic subjects compared to the asymptomatic subjects $\left(35.3 \%\right.$ vs $13.2 \% ; x^{2}=25.874$; $P<0.001)$. In the group examined, $64.3 \%(54 / 84)$ of the Blastocystis-positive patients were symptomatic and $35.7 \%$ (30/84) were asymptomatic. Blastocystis sp. represented the only intestinal parasite in 51 of these symptomatic patients. The common symptoms among patients infected exclusively with Blastocystis sp. were abdominal pain (76.4\%), flatulence (41.1\%) and diarrhoea (21.5\%). Moreover, $5.8 \%$ and $3.9 \%$ of these patients had nausea/ vomiting and constipation, respectively. Twenty one of the symptomatic patients $(41.2 \%)$ had two or more GI symptoms while $35.3 \%$ had only one symptom. Abdominal pain $\left(35.9 \%\right.$ vs $\left.14.9 \% ; x^{2}=22.023 ; P<0.001\right)$ and flatulence $\left(49.1 \%\right.$ vs $\left.17.5 \% ; x^{2}=27.197 ; P<0.001\right)$ were the significant symptoms associated with Blastocystis infection observed in the subjects studied (Table 2).

\section{Discussion}

In the present study, the prevalence of Blastocystis infection was $22.1 \%$, which is within the range of the prevalence rate of previous studies in Libya $[7,8,11,12]$. The prevalence of Blastocystis infection in Sebha was reported to range between $18.5 \%$ and $26.2 \%$ [7,8]. Moreover, studies from other regions of Libya have reported a prevalence of $29.6 \%$ in Sirt city [11] and 6.7\% among schoolchildren in Derna [12]. Most Libyan medical practitioners are not familiar with Blastocystis infection in humans, even though Blastocystis infection was commonly found in hospitalized patients. Moreover, knowledge on the epidemiology and transmission of Blastocystis sp. is not widely known and thus the laboratory detection of Blastocystis sp. in stool samples is not routinely carried out.

Shedding of Blastocystis sp. from infected individuals especially asymptomatic carriers could be a source of infection in the region. An enormous increase of foreign workers from neighbouring countries (mainly Egypt, Sudan and Chad) and travellers may have contributed to the high prevalence of intestinal parasites especially Blastocystis sp. in the country. However, the prevalence of intestinal parasitic infections is expected to increase due to the civil unrest and war in Libya since early 2011. Although there were other intestinal protozoa parasites found in these participants, Blastocystis sp. was the most common. Other intestinal protozoa found included Giardia duodenalis, Cryptosporidium spp., Entamoeba histolytica, Entamoeba coli (not reported in the results). Moreover, Enterobius vermicularis was the only helminth detected in one patient. It seems that the arid climate of the study area is not favourable for the development of helminth parasites which need either moist soil (such as soil-transmitted helminths) or aquatic environment where intermediate hosts such as snails, fish or aquatic plants can be found (such as Schistosoma spp., Liver flukes, Diphyllobothrium latum, ... .etc.) [13].

The present study is the first to provide information about the predictors of Blastocystis infection in Libya. Previous reports from different countries have shown that Blastocystis infections are associated with several factors such as the consumption of contaminated food and water, close contact with animals, poor personal hygiene, inadequate sanitation, geographical distribution, agricultural activities and seasonal influences [3,4,14-16]. Our findings showed that adult participants (aged $\geq 18$ years) were almost 4 times more likely to be infected with Blastocystis sp. It was also found that males were more prone to be infected than females. Several studies have also reported a significantly higher prevalence in male than female patients in Libya [8,17] and other countries $[5,18]$. Outdoor activities by the adult males may also explain the significantly higher prevalence of Blastocystis infections among these groups. Previous studies have found significantly higher infection rates in adults than in children with the highest prevalence rate among young adults aged between 18 and 30 years $[1,19,20]$. In contrast, other reports found a higher prevalence rate in children and females as compared to adults and males [21-23]. Moreover, a recent study has reported a significant reduction in the Blastocystis infection prevalence rate in older children when compared with younger children [9]. These contradictory findings suggest that the distribution of Blastocystis infection shows spatial 
heterogeneity with respect to age or sex factors. The age and gender correlations identified in this study may not represent physiological properties intrinsic to those hosts, but rather may be caused by the variation in environmental conditions associated with age and gender.

In the same vein, the present study showed that occupational status of the participants was a significant predictor of Blastocystis infection, with those employed having a greater odds for infection compared to those unemployed. The high prevalence rate among employed participants may indicate a higher exposure to the source of infection at the work places including the food and environment. Supporting this conjecture, a high prevalence rate of Blastocystis infection (35.5\%) was reported among food handlers in Libya [24].

Our findings showed a significant association between the educational level of the participants and the prevalence of Blastocystis infection. Improvement of hygienic conditions and sanitary practices with education is well documented and several previous studies have identified that the low level of education as a significant risk factor of blastocytosis and other parasitic infections [3,25,26]. Another significant finding of the present study that was associated with the risk of Blastocystis infection was the family size. Participants belong to large families ( $\geq 7 \mathrm{mem}$ bers) were at lower odds for Blastocystis infection compared to those from smaller families. This finding is contrary to previous studies that reported a significant association between Blastocystis infection and the presence of other infected family members [27] and this has been attributed to the horizontal spread or the focal transmission of infection among family members in the vicinity of the home. Nevertheless, these significant associations of Blastocystis infection with the level of education and family size were not confirmed by the multiple logistic regression analysis.

Blastocystis infection was noted to be transmitted through the faecal-oral route [28], contaminated water [3,27], and food $[29,30]$. The environmentally resistant cyst represents the transmissible form of the parasite [4,31,32]. Drinking contaminated water, especially surface water, was reported to be a significant risk factor for Blastocystis infection $[3,14,27,33]$. The current study found that all houses had a piped water supply (groundwater) and almost two-thirds of the participants use this water for drinking and other domestic household purposes such as cooking without any physical or chemical treatment. However, we found no significant difference in the prevalence of Blastocystis infection between those who use treated water and those who use untreated water. This may indicate that the level of Blastocystis contamination in groundwater is low. Data about the presence of waterborne parasites in drinking water and sewage in Sebha city are not available. Similarly, the present study found no significant association between
Blastocystis infection and contact with animals. A significantly higher prevalence of Blastocystis infection among people having close contact with animals was reported by previous studies $[15,16]$. Molecular studies have also showed that Blastocystis isolates from animals are found in the human host $[15,34,35]$. Hence, the possibility of waterborne zoonotic transmission of Blastocystis sp. was highly suggested [16].

Sebha city has adequate public services and other infrastructure with the exception of health structures. It was observed that the garbage and sewage from the city are discharged without proper treatment in the nearby desert land and this may have an influence on the contamination of the environment with cysts of Blastocystis sp. and other enteric pathogenic parasites (e.g. Cryptosporidium, Giardia). Moreover, this unhygienic practice may facilitate the transfer of the infective stages through wind into the food and environment. Besides, Blastocystis infection was reported to be most common during summer [8], where, the hot and dry climate may increase the transmission of the resistant forms (cyst or oocyst) of enteric protozoa (especially Blastocystis sp.) in the dusty environments of this city. This may be also partially explain the higher prevalence in males, who work more outdoors and therefore, have more exposure to the source of infections compared to females.

Numerous studies have examined the pathogenic potential of Blastocystis sp. by investigation its prevalence in symptomatic and asymptomatic groups, and have thus either supported or denied pathogenic significance of this protozoan [21,36-38]. In the present study, we found a strong statistical association between the infection and the development of gastrointestinal symptoms $(P<0.001)$. The most common symptoms in symptomatic patients were abdominal pain $76.4 \%$, flatulence $41.1 \%$, and diarrhoea $21.5 \%$. These findings are consistent with previous studies [5,38,39]. In Saudi Arabia, abdominal pain (87.9\%), constipation (32.2\%) and diarrhoea (23.4\%) were reported among 12,136 Blastocystis-infected patients [20]. Moreover, abdominal pain (76.9\%), diarrhoea (50\%) and distention (32.6\%) were found to be associated with Blastocystis infection among hospitalized children in Turkey [39]. Similarly, abdominal pain, recurrent diarrhoea, cramps, anorexia, and fatigue were significantly associated with Blastocystis infection among preschool children in Jordan [5]. Moreover, the majority of the patients in our study had two gastrointestinal symptoms, which is consistent with several reports among patients infected with Blastocystis sp. $[6,18]$. However, a previous report on the Blastocystis associated symptoms among patients from Sebha city found a higher number of diarrhoea cases followed by abdominal pain, flatulence and nausea or vomiting [8].

It has been suggested that Blastocystis sp. may be an opportunistic pathogen in immunocompromised individuals 
including AIDS patients and individuals with cancer $[40,41]$. However, the correlation between clinical symptoms and Blastocystis in immunocompromised individuals could not be delineated and the possibility of other unidentified etiological agents, especially viruses, toxins, and non infectious causes could not be assessed. As a limitation of the present study, data on the immunological status of the participants were not available. The study may have incorporated a selection bias, as only samples from patients submitted to the Sebha Central Laboratory were examined. This limitation is difficult to overcome, as collecting faecal samples from the general population of this Libyan community has been found to be difficult. However, Sebha Central Laboratory receives samples from symptomatic and asymptomatic individuals including those who come for routine medical check ups requested by public and private organizations and educational institutions. Thus, we may speculate that the findings of the present study can be generalized to the Sebha population. On the other hand, these findings cannot be generalized to the entire Libyan population. However, further studies are required to confirm these conjectures.

\section{Conclusions}

This study reveals a high prevalence of Blastocystis infection among individuals seeking health care in Sebha city in Libya. The age of $\geq 18$ years and occupational status were the significant predictors of infection in this population. A significant association between symptoms and Blastocystis infections was reported. Detection of Blastocystis sp. is not routinely performed in most Libyan laboratories; hence, laboratory technicians need to be trained in the detection of Blastocystis sp. in clinical samples. Further studies on animal and environmental isolates are required to identify different transmission routes and reservoirs of Blastocystis sp. In addition, more research especially those that utilize advanced molecular techniques are highly recommended in future attempts to reveal the clinical significance of the different Blastocystis sp. subtypes.

\section{Competing interests}

The authors declare that they have no competing interests.

\section{Authors' contributions}

AMA was involved in all phases of the study, including data collection and analysis, interpretation, and write up of the manuscript; II and HMA designed and supervised the study and; AMA, AHK, AA were involved in the collection and laboratory examination of samples. MJW and JS revised the analysis and manuscript. All authors read and approved the final manuscript.

\section{Acknowledgements}

The authors wish to thank the staff of Sebha Central Laboratory, Medical Laboratory Science Department (Faculty of Engineering and Technology) and Sebha Medical Center, Sebha, Libya, for their kind help and cooperation. This study was supported by the University of Malaya research grants (RG187/10HTM and PS230/2010B).

\section{Author details}

${ }^{1}$ Department of Parasitology, Faculty of Medicine, University of Malaya, Kuala Lumpur 50603, Malaysia. ²Department of Parasitology, Faculty of Medicine, University of Sebha, Sebha, Libya. ${ }^{3}$ Department of Biology, Faculty of Natural and Applied Sciences, Umaru Musa Yar'adua University, Katsina, Katsina State, Nigeria. ${ }^{4}$ School of Postgraduate Studies and Research, International Medical University, Bukit Jalil, Kuala Lumpur 57000, Malaysia. ${ }^{5}$ Department of Parasitology, Faculty of Medicine and Health Sciences, Sana'a University, Sana'a, Yemen

Received: 20 December 2012 Accepted: 11 March 2013

Published: 8 April 2013

\section{References}

1. Ashford R, Atkinson E: Epidemiology of Blastocystis hominis infection in Papua New Guinea: age-prevalence and association with other parasites. Annals Trop Med Parasitol 1992, 86:129-136.

2. Zierdt $\mathrm{CH}$, Zierdt WS, Nagy B: Enzyme-linked immunosorbent assay for detection of serum antibody to Blastocystis hominis in symptomatic infections. J Parasitol 1995, 81:127-129.

3. Abdulsalam AM, Ithoi I, AI-Mekhlafi HM, Ahmed A, Surin J, Mak JW: Drinking water is a significant predictor of Blastocystis infection among rural Malaysian primary schoolchildren. Parasitol 2012, 139:1014-1020.

4. Stenzel D, Boreham P: Blastocystis hominis revisited. Clin Microbiol Rev 1996, 9:563-584.

5. Nimri L, Batchoun R: Intestinal colonization of symptomatic and asymptomatic schoolchildren with Blastocystis hominis. J Clin Microbiol 1994, 32:2865.

6. El-Shazly AM, Abdel-Magied AA, El-Beshbishi SN, El-Nahas HA, Fouad MA, Monib MS: Blastocystis hominis among symptomatic and asymptomatic individuals in Talkha Center, Dakahlia Governorate, Egypt. J Egypt Soc Parasitol 2005, 35:653-666.

7. Al-Fellani MA, Abdullrahman DM, Khan AH, Abousaif AA: Prevalence of intestinal parasites in Sebha, Libya. Garyounis Med J 2005, 22:56-60.

8. Al-Fellani MA, Khan AH, Al-Gazoui RM, Zaid MK, Al-Ferjani MA: Prevalence and clinical features of Blastocystis hominis infection among patients in Sebha, Libya. Sultan Qaboos Univ Med J 2007, 7:35.

9. Pipatsatitpong D, Rangsin R, Leelayoova S, Naaglor T, Mungthin M: Incidence and risk factors of Blastocystis infection in an orphanage in Bangkok Thailand. Parasit Vectors 2012, 14:37.

10. Cheesbrough M: District laboratory practice in tropical countries. 2nd edition Cambridge: Cambridge University press; 2004

11. Salem RAA, Abdullah ME, Abdulgader AE: Intestinal protozoa in Libyan patients in Sirt. Jamahiriya Med J 2006, 6:59-61.

12. Sadaga $G$, Kassem $H$ : Prevalence of intestinal parasites among primary schoolchildren in Derna District, Libya. J Egypt Soc Parasitol 2007, 37:205.

13. Brooker S, Kabatereine NB, Tukahebwa EM, Kazibwe F: Spatial analysis of the distribution of intestinal nematode infections in Uganda. Epidemiol Infect 2004, 132:1065-1071.

14. Leelayoova S, Siripattanapipong S, Thathaisong U, Naaglor T, Taamasri $P$, Piyaraj $P$, Mungthin M, Drinking water: A possible source of Blastocystis spp. subtype 1 infection in schoolchildren of a rural community in Central Thailand. AmJTrop Med Hyg 2008, 79:401-406.

15. Parkar U, Traub RJ, Vitali S, Elliot A, Levecke B, Robertson I, Geurden T, Steele J, Drake B, Thompson R: Molecular characterization of Blastocystis isolates from zoo animals and their animal-keepers. Vet Parasitol 2010, 169:8-17.

16. Lee LI, Chye TT, Karmacharya BM, Govind SK: Blastocystis sp.: waterborne zoonotic organism, a possibility? Parasit Vectors 2012, 5:130.

17. Khan AH, Al-Fellani MA, Rugaia A, Ali D, Omran A: A comparsion of three different methods for the diagnosis of Blastocystis hominis. Jamahiriya Med J 2008, 8:31-34.

18. Wang KX, Li CP, Wang J, Cui YB: Epidemiological survey of Blastocystis hominis in Huainan City, Anhui Province, China. World J Gastroenterol 2002, 8:928-932.

19. Yaicharoen R, Sripochang S, Sermsart B, Pidetcha P: Prevalence of Blastocystis hominis infection in asymptomatic individuals from Bangkok, Thailand. Southeast Asian J Trop Med Public Health 2005, 36:17-20.

20. Qadri S, Al-Okaili GA, Al-Dayel F: Clinical significance of Blastocystis hominis. J Clin Microbiol 1989, 27:2407-2409.

21. Martin-Sanchez A, Canut-Blasco A, Rodriguez-Hernandez J, Montes-Martinez I, Garcia-Rodriguez J: Epidemiology and clinical significance of Blastocystis 
hominis in different population groups in Salamanca (Spain). Eur $J$ Epidemiol 1992, 8:553-559.

22. Eleonor TB, Vincente YB, Winifreda UD, Hyun HK, Dong C: Infection status of intestinal parasites in children living in residential institutions in Metro Malino. The Philippines. Korean J Parasitol 2004, 42:67-70.

23. Senay H, MacPherson D: Blastocystis hominis: epidemiology and natural history. J Infect Dis 1990, 162:987-990.

24. Fathy FM: A study on Blastocystis hominis in food-handlers: diagnosis and potential pathogenicity. J Egypt Soc Parasitol 2011, 41:433-453.

25. Quihui L, Valencia ME, Crompton DWT, Phillips S, Hagan P, Morales G, Diaz Camacho SP: Role of the employment status and education of mothers in the prevalence of intestinal parasitic infections in Mexican rural schoolchildren. BMC Publ Health 2006, 6:225.

26. Okyay P, Ertug S, Gultekin B, Onen O, Beser E: Intestinal parasites prevalence and related factors in school children, a western city sampleTurkey. BMC Publ Health 2004, 4:64.

27. Anuar TS, Ghani MK, Azreen SN, Salleh FM, Moktar N: Blastocystis infection in Malaysia: Evidence of waterborne and human-to-human transmissions among the Proto-Malay, Negrito and Senoi tribes of Orang Asli. Parasit Vectors 2013, 6:40.

28. Yoshikawa H, Yoshida K, Nakajima A, Yamanari K, I watani S, Kimata I: Fecal-oral transmission of the cyst form of Blastocystis hominis in rats. Parasitol Res 2004, 94:391-396.

29. Casemore DP: Foodborne protozoal infection. Lancet 1990, 336:1427-1432.

30. Smith H, Nichols R: Zoonotic protozoa-food for thought. Parasitologia 2006, 48:101.

31. Samie A, Guerrant R, Barrett L, Bessong P, Igumbor E, Obi C: Prevalence of intestinal parasitic and bacterial pathogens in diarrhoeal and nondiarroeal human stools from Vhembe district, South Africa. J Health Popul Nutr 2009, 27:739.

32. Singh M, Suresh K, Ho L, Ng G, Yap E: Elucidation of the life cycle of the intestinal protozoan Blastocystis hominis. Parasitol Res 1995, 81:446-450.

33. Taamasri P, Mungthin M, Rangsin R, Tongupprakarn B, Areekul W, Leelayoova S: Transmission of intestinal blastocystosis related to the quality of drinking water. Southeast Asian J Trop Med Public Health 2000, 31:112-117.

34. Noel C, Dufernez F, Gerbod D, Edgcomb VP, Delgado-Viscogliosi P, Ho LC, Singh M, Wintjens R, Sogin ML, Capron M: Molecular phylogenies of Blastocystis isolates from different hosts: implications for genetic diversity, identification of species, and zoonosis. J Clin Microbiol 2005, 43:348-355.

35. Yoshikawa H, Wu Z, Nagano I, Takahashi Y: Molecular comparative studies among Blastocystis isolates obtained from humans and animals. J Parasitol 2003, 89:585-594.

36. Cirioni O, Giacometti A, Drenaggi D, Ancarani F, Scalise G: Prevalence and clinical relevance of Blastocystis hominis in diverse patient cohorts. Eur J Epidemiol 1999, 15:387-391.

37. Udkow MP, Markell EK: Blastocystis hominis: prevalence in asymptomatic versus symptomatic hosts. J Infect Dis 1993, 168:242-244.

38. Tan KSW: New Insights on classification, identification, and clinical relevance of Blastocystis spp. Clin Microbiol Rev 2008, 21:639-665.

39. Kaya S, Cetin ES, Aridogan B, Arikan S, Demirci M: Pathogenicity of Blastocystis hominis, a clinical reevaluation. Turkiye Parazitol Derg 2007, 31:184-187.

40. Kurniawan A, Karyadi T, Dwintasari S, Sari I, Yunihastuti E, Djauzi S, Smith H: Intestinal parasitic infections in HIV/AIDS patients presenting with diarrhoea in Jakarta, Indonesia. Trans R Soc Trop Med Hyg 2009, 103:892-898.

41. Horiki N, Kaneda Y, Maruyama M, Fujita Y, Tachibana H: Intestinal blockage by carcinoma and Blastocystis hominis infections. Am J Trop Med Hygiene 1999, 60:400-402.

doi:10.1186/1756-3305-6-86

Cite this article as: Abdulsalam et al:: Prevalence, predictors and clinical significance of Blastocystis sp. in Sebha, Libya. Parasites \& Vectors 2013 6:86.

\section{Submit your next manuscript to BioMed Central and take full advantage of:}

- Convenient online submission

- Thorough peer review

- No space constraints or color figure charges

- Immediate publication on acceptance

- Inclusion in PubMed, CAS, Scopus and Google Scholar

- Research which is freely available for redistribution 